\title{
EL DERECHO DE ACCESO A LOS MEDIOS DE COMUNICACIÓN PÚBLICOS DE LOS GRUPOS SOCIALES Y POLÍTICOS SIGNIFICATIVOS EN EL ESTADO SOCIAL Y DEMOCRÁTICO DE DERECHO*
}

\author{
ANTONIO MAGDALENO ALEGRÍA \\ Profesor de Derecho Constitucional \\ Universidad de Cantabria
}

SUMARIO

I. Introducción.

II. El derecho de acceso a los medios de comunicación dependientes del Estado como garantía específica de las libertades de expresión e información en el Estado social y democrático de Derecho.

III. El acceso a los medios de comunicación públicos en el ordenamiento jurídico español.

IV. Algunas propuestas de lege ferenda.

\section{INTRODUCCIÓN}

La situación de los medios de comunicación públicos en España y la necesidad de su reforma continúan siendo objeto de discusión entre los juristas, la clase política o los profesionales de la información. El gobierno elegido tras las elecciones de 2004 pretende abordar de nuevo esta cuestión y, para ello, creó

* Nota del autor: Cuando el presente artículo se encuentra en imprenta, ha sido aprobada la ley 17/2006, de 5 de junio, de la Radio y Televisión pública. Por ello, no se hace referencia al citado texto legal. En cualquier caso, muchas de las apreciaciones y propuestas que se realizan en este artículo siguen plenamente vigentes. 
mediante el Real Decreto 744/2004, de 23 de abril, el Consejo para la reforma de los medios de comunicación de titularidad del Estado ${ }^{1}$.

Entre las distintas cuestiones que el citado Consejo abordó en su informe se encuentra el acceso de los grupos sociales y políticos significativos a los medios de comunicación del Estado, dado que el artículo 20.3 de la Constitución establece que la ley garantizará el citado acceso, respetando el pluralismo de la sociedad y de las diversas lenguas de España.

El presente artículo tratará de ver cómo el reconocimiento y garantía del acceso a los medios de comunicación dependientes del Estado supone una revisión del modelo liberal de comunicación pública y, por ello, la Constitución española de 1978 optó por una relectura de las libertades de comunicación pública teniendo en cuenta las funciones sociales o políticas que desempeñan en el Estado social y democrático de Derecho.

Una vez defendida esta idea, se expondrá, lo más resumidamente posible, la actual configuración del acceso a los medios de comunicación públicos en el ordenamiento jurídico español con el objeto de tratar de demostrar que su regulación está todavía lejos de ser coherente con la citada forma de Estado.

Por último, se efectuarán algunas propuestas de lege ferenda con la finalidad de realizar una ordenación del acceso lo más coherente posible con la forma de Estado establecida en el artículo 1 de la Constitución, esto es, con el Estado social y democrático de Derecho.

\section{EL DERECHO DE ACCESO A LOS MEDIOS DE COMUNICACIÓN DEPENDIENTES DEL ESTADO COMO GARANTÍA ESPECÍFICA DE LAS LIBERTADES DE EXPRESIÓN E INFORMACIÓN EN EL ESTADO SOCIAL Y DEMOCRÁTICO DE DERECHO}

Como afirma Stein, todo derecho fundamental tiene su raíz histórica en la falta previa de libertad contra la que se dirige. De ahí que para lograr la comprensión concreta de cada derecho fundamental haya que investigar su significado originario. Pero no basta con descubrir su origen; es necesario, además, seguir su posterior evolución hasta nuestros días ${ }^{2}$.

Las libertades de expresión e información no son ajenas al aludido proceso de evolución de los derechos fundamentales. Así, en el Estado liberal, las libertades de expresión e información se concibieron como derechos de defensa sobre los que, en principio, el Estado no podía ejercer ningún tipo de injerencia ${ }^{3}$. La necesidad de su protección se justificó, entre otras razones, por-

1 El informe para la reforma de los medios de comunicación de titularidad del Estado se presentó el 4 de febrero de 2005.

2 Véase STEIN, E: Derecho político, Aguilar, Madrid, 1973, p. 126.

3 En este sentido, fue enormemente significativa la declaración de derechos del Buen Pueblo de Virginia, de 12 de junio de 1776, donde se dispuso que: "la libertad de prensa es uno de los baluartes de la libertad y no puede ser restringida jamás a no ser por gobiernos despóticos”. En 
que la libertad de expresión constituía un método para alcanzar la verdad ${ }^{4}$, se erigía como un cauce pacífico para dirimir las divergencias inherentes a toda sociedad plural y era un instrumento para ilustrar a la población en general 5 . Su reconocimiento se realizó exclusivamente desde el punto de vista del sujeto emisor del mensaje, esto es, sólo se protegió al sujeto emisor de informaciones $\mathrm{u}$ opiniones, y, por ende, no se reconoció el derecho a recibir opiniones o informaciones. El modelo liberal de comunicación pública no se preocupó de los presupuestos sociales necesarios para el ejercicio de las libertades públicas y, por ello, sólo las personas que podían sufragar los altos costes que generaba la prensa podían expresar efectivamente sus ideas u opiniones ante los demás y, como más tarde criticó la doctrina marxista, sólo defendían sus intereses ${ }^{6}$. Asimismo la situación descrita generó que si bien estas libertades estaban reconocidas a todos los ciudadanos, no podían ser ejercidas efectivamente de manera igual, con lo que las opiniones de los que no poseían medios de comunicación no podían ser transmitidas para que fueran escuchadas por todos.

Con la llegada del Estado democrático, y el consecuente reconocimiento de los derechos de sufragio y de asociación política, se constató la importancia de las libertades de expresión y de prensa para el ejercicio del autogobierno de los ciudadanos. Concretamente, la prensa, al hacer públicos los asuntos generales y las ideas políticas, permite el control del poder político y fomenta el asociacionismo de los ciudadanos ${ }^{7}$. Del mismo modo, las libertades de expresión y

Francia, el artículo 11 de la Declaración de los derechos del Hombre, de 26 de agosto de 1789, dispuso que: "la libre comunicación de los pensamientos y de las opiniones es uno de los derechos más preciosos del hombre; todo ciudadano puede, por tanto, hablar, escribir e imprimir libremente, salvo la responsabilidad que el abuso de esta libertad produzca en los casos determinados en la ley". En nuestro país, el artículo 371 de la Constitución de Cádiz, de 19 de marzo de 1812, proclamó que: "todos los españoles tienen la libertad de escribir, imprimir y publicar sus ideas políticas, sin licencia, revisión o aprobación alguna anterior a la publicación, bajo las restricciones y responsabilidad que establezca la ley".

4 En este sentido, MILTON mantuvo que «todas las opiniones, (...) e incluso todos los errores, conocidos, leídos, comparados, son de especial provecho y ventajosos para el beneficio neto de la verdad más segura". Asimismo, en su justificación contra la censura previa argumentó que ésta causará: «un notable desaliento en el mundo de la ciencia y una paralización del avance de la verdad, no sólo fatigando y dejando tocadas nuestras facultades en lo ya conocido sino, incluso, desmoronando y obstaculizando ulteriores descubrimientos que pudieran alcanzarse tanto en el campo de la ciencia religiosa como en la laica". Véase MILTON, J.: Aeropagítica, Torres de Goyanes, Madrid, 2001, p. 67 y 52.

5 Respecto de la última cuestión, en el preámbulo del Decreto IX de 10 de noviembre de 1810 dictado por las Cortes de Cádiz se dispuso que el reconocimiento de la libertad de imprenta es "un instrumento para ilustrar a la Nación en general", fruto de la creencia de los liberales de que la libre difusión de las ideas tendría un efecto muy beneficioso en la educación de la población.

6 Véase MONZÓN ARRIBAS, C.: “Orígenes y primeras teorías sobre la opinión pública: liberalismo y el marxismo", Revista de estudios políticos, núm. 44, 1985, p. 109.

7 En este sentido, son enormemente esclarecedoras las siguientes palabras de Alexis DE TOCQUEVILLE: «en nuestros días, un ciudadano oprimido no tiene más que un medio para defenderse, que consiste en dirigirse a la nación entera, y si es sorda, al género humano. Solamente hay un medio para hacerlo: la prensa. Así, la libertad de prensa es infinitamente más preciosa en las naciones democráticas que en todas las demás, ella sola cura la mayor parte de los males que puede producir 
de prensa son esenciales para el sistema representativo dado que permiten a los electores conocer a los candidatos y elegirlos con fundamento.

Sin embargo, a medida que avanza el Estado democrático, también se fue consciente de algunos efectos negativos. Como señala el profesor FISS desde el prisma de la Constitución norteamericana, la doctrina liberal-democrática de la libertad de expresión protege la autonomía mediante la limitación de la acción del Estado, es decir, busca evitar la reglamentación de los contenidos de la expresión. Se protege la autonomía no como un bien en sí mismo o por ser un medio de autorrealización personal, sino porque en la primera enmienda subyacen unos valores sociales o políticos cuya protección se considera necesaria. Con la protección de la autonomía, en principio, se producirá un debate más vigoroso, desinhibido y completamente abierto $^{8}$. Se considera que la libertad de expresión es un medio o instrumento de autodeterminación colectiva, la libre expresión de las opiniones permite a las personas votar libremente conociendo todas las opciones y las informaciones relevantes. Se piensa que el debate libre es una condición previa y esencial para el gobierno democrático. En definitiva, la primera enmienda busca promover la democracia protegiendo la autodeterminación colectiva.

Como advierte el profesor norteamericano, en la nueva sociedad de la información y de los medios de comunicación de masas, ya no se da esta situación y, por consiguiente, entiende que deben ser reformulados los postulados de la teoría liberal-democrática de la libertad de expresión ${ }^{9}$. Partiendo de esta nueva situación, defiende la idea de que la autonomía y el debate público pueden ser antagónicos, la autonomía puede ser inadecuada para generar un debate lo suficientemente rico para la democracia. El debate público está dominado por las redes informativas de la televisión y por un cierto número de medios de la prensa escrita ${ }^{10}$. Los medios de comunicación desempeñan un papel decisivo a la hora de determinar qué cuestiones son debatidas y cómo han de llevarse a cabo tales controversias. La protección de la autonomía de los medios de comunicación por la teoría liberal-democrática va a tener como

la igualdad. La igualdad aísla y debilita a los hombres, pero la prensa pone al lado de cada uno de ellos un arma poderosa, de la que puede hacer uso el más débil y más aislado. (...) La prensa es, por excelencia, el instrumento democrático de la libertad". Asimismo, mantuvo que "en los países democráticos sucede a menudo (...) que un gran número de hombres que tienen el deseo o la necesidad de asociarse no pueden hacerlo porque, al ser todos muy pequeños y al estar perdidos en la multitud, no se ven y no saben donde encontrarse. Aparece el periódico que saca a la luz el sentimiento o la idea que se había presentado simultáneamente, pero por separado, a cada uno de ellos. Todos se dirigen enseguida hacia la luz, y esos espíritus errantes que se buscaban en las tinieblas desde hace mucho tiempo, se encuentran al fin y se reúnen". Véase DE TOCQUEVILLE, A.: La democracia en América, Aguilar, Madrid, 1989, pp. 153 y 382.

8 Véase New York Times v. Sullivan, 376 U.S. 254, 270 (1964).

9 Véase FISS, O.: "Free Speech and Social Structure", Iowa Law Review, núm. 71, 1986, p. 1405 y ss.

10 Además de la experiencia norteamericana, un modelo paradigmático de la situación criticada por FISS es el italiano. Sobre el citado modelo, véase CARETTI, P.: Diritto dell'informazione e della comunicazione. Spampa, radiotelevisioni, teatro e cinema, Il molino, Bologna, 2001, p. 77 y ss. 
consecuencia que el debate público esté influenciado decisivamente por los que dominan la estructura social. El mercado no asegura que las opiniones de todos sean escuchadas y, por lo tanto, no se produce un debate vigoroso, desinhibido y completamente abierto ${ }^{11}$. La cuestión no es un fallo del mercado, sino el alcance del mercado.

La situación descrita tiene respuesta en el Estado en social y democrático de Derecho pues los poderes públicos no sólo tienen la posibilidad, sino el deber, de corregir las circunstancias sociales que impiden el disfrute efectivo de los derechos fundamentales. En el ordenamiento constitucional español, la acción positiva del Estado social se fundamenta en la cláusula de Estado social del artículo 1.1 de la Constitución en relación con el mandato genérico del artículo 9.2 de la misma. En aplicación de lo anterior a las libertades de comunicación pública, el Estado debe garantizar que la transmisión de ideas y de informaciones sea ejercida efectivamente por todos los ciudadanos y no sólo por unos pocos, es decir, el Estado debe crear las condiciones necesarias para que todos participen efectivamente en el debate público y expongan sus ideas e informaciones ante la opinión pública.

Los cambios enunciados también afectan a la dogmática de los derechos fundamentales. La dogmática liberal de los derechos fundamentales es insuficiente para dar explicación a las transformaciones aludidas, dado que, como se ha enunciado, las libertades de expresión e información eran concebidas como libertades frente al Estado. Con el Estado social y democrático de Derecho los derechos fundamentales pasan a tener un doble carácter, subjetivo y objetivo o institucional, lo que supone según esta segunda nueva perspectiva que los derechos fundamentales constituyen principios o valores superiores del ordenamiento jurídico que como tales suponen una obligación por parte del Estado para actuar positivamente ${ }^{12}$. Dicho de otro modo, la dogmática institucional de

11 En opinión de FISS, el mercado restringe la presentación de cuestiones de interés e importancia pública de las dos maneras siguientes:

De un lado, el mercado privilegia a determinados grupos selectos, por medio de programas, periódicos y revistas especialmente receptivos a sus necesidades y deseos, entre los que se destacarán los siguientes: el primer grupo se compone por quienes poseen el capital suficiente para adquirir o poseer un medio de comunicación, bien sea una cadena de televisión, un periódico o una revista. Otro grupo está integrado por los que controlan los presupuestos publicitarios de varias empresas. Así, por ejemplo, los intereses de las compañías que se publiciten en los medios van influir de manera determinante en las líneas editoriales de éstos. Y el tercer grupo está formado por los consumidores de los productos publicitados.

De otro, el mercado introduce en la toma de decisiones editoriales y de programación de los medios de comunicación, factores más relacionados con su rentabilidad económica o la eficiencia que se les asigna (para ver las cosas desde un punto de vista) pero que tienen poco que ver con las necesidades democráticas del electorado. Véase FISS, O.: "Why the State?", Harvard Law Review, núm. 100, 1987 p. 787 y ss.

12 Doctrinalmente defienden la teoría institucional de las libertades comunicativas de comunicación pública, entre otros, SOLOZÁBAL ECHAVARRÍA, J.J.: “Acerca de la doctrina del Tribunal Constitucional en materia de libertad de expresión", Revista de Estudios Políticos, núm. 77, 1992, p. 237 y ss, BACIGALUPO, E.: "Colisión de derechos fundamentales y justificación en el delito de injuria", Revista Española de Derecho Constitucional, núm. 20, mayo-agosto 1987, p. 94, BUSTOS GIL- 
los derechos fundamentales es la que responde a la nueva estructura social y democrática del Estado. En referencia a las libertades de expresión e información la dimensión subjetiva se relaciona con el libre desarrollo de la personalidad, y la objetiva con la libre formación de la opinión pública. El Tribunal Constitucional ha admitido en su numerosa jurisprudencia sobre esta materia que las libertades de expresión e información no sólo son derechos individuales de cada ciudadano, sino que también significan el reconocimiento y la garantía de una institución política fundamental que es la opinión pública libre que, a su vez, es esencial para el pluralismo político propio del Estado democrático. Así, por ejemplo, en la STC 127/1994, de 5 de mayo, el Tribunal Constitucional sostiene que: "en diversas ocasiones hemos reiterado que los derechos de libre expresión e información, en su dimensión de derechos de libertad, significan básicamente ausencia de interferencias e intromisiones ilegítimas en el proceso de comunicación, pero, a la vez, en su dimensión institucional, suponen una garantía de una opinión pública libre y del mantenimiento del pluralismo político ${ }^{13}$. El reconocimiento por parte del Tribunal Constitucional de la doble dimensión de las libertades de expresión e información tiene, entre otras, dos consecuencias de gran importancia: de un lado, se da eficacia jurídica a las funciones políticas o sociales que las aludidas libertades desempeñan en el seno del Estado social y democrático de Derecho, frente a la teoría liberal de los derechos fundamentales que no les concedía ninguna consecuencia jurídica. Por ello, el núcleo esencial de las libertades de expresión e información no sólo se compone por la dimensión subjetiva del derecho, sino también de una dimensión objetiva o institucional que los poderes públicos, incluido el legislador, deberán respetar, realizar y proteger, a la hora de interpretar, delimitar y limitar estas libertades públicas ${ }^{14}$. De otro lado, la di-

BERT, R.: "El concepto de libertad de información a partir de su distinción de la libertad de expresión", Revista de Estudios Políticos, núm. 85, 1994, p. 262 y ss, CARRILLO LÓPEZ, M.: Límites a la libertad de prensa en la Constitución de 1978, PPU, Barcelona, 1987, p. 146 y ss, JAÉN VALLEJO, M.: Libertad de expresión y delitos contra el honor, Constitución y Leyes, Madrid, 1992, p. 42 y ss, MARTÍNEZ SOSPEDRA, M.: Libertades públicas, Fundación Universitaria San Pablo CEU, Valencia, 1993, p. 239 y ss, DE DOMINGO PÉREZ, T.: ¿Conflictos entre derechos fundamentales?: un análisis desde las relaciones entre los derechos a la libre expresión e información y los derechos al honor y a la intimidad, Centro de Estudios Constitucionales, Madrid, 2001, p. 321 y ss, CATALÁ I BAS, A. H.: Libertad de expresión e información. La jurisprudencia del Tribunal Europeo de los Derechos Humanos y su recepción por el Tribunal Constitucional, hacia un derecho europeo de los derechos bumanos, Revista general de derecho, Valencia, 2001, p. 75 y ss, SORIANO DÍAZ, R.: Las libertades públicas: significado, fundamentos y estatuto jurídico, Tecnos, Madrid, 1990, p. 108 y ss, LÓPEZ ULLA, J.M.: Libertad de informar y el derecho a expresarse. La jurisprudencia del Tribunal Constitucional, Universidad de Cádiz, Cádiz, 1994, 31 y ss, MUÑOZ MACHADO, S.: Libertad de prensa y procesos por difamación, Ariel, Barcelona, 1988, p. 34 y ss, DE CARRERAS SERRA, F.: "La libertad de expresión: un derecho constitucional", en VV.AA., Libertad de expresión: Anuario 1990, PPU, Barcelona, 1991, p. 27 y ss, VERDUGO GÓMEZ DE LA TORRE, I.: "Los límites entre la libertad de expresión y los derechos de la personalidad. Especial referencia a la problemática jurídico-penal", Anuario de derecho penal y de ciencias penales, núm. II, vol. XLIV, 1991, p. 345.

13 Véase STC 127/1994, de 5 de mayo, FJ 5. ${ }^{\circ}$

14 Un claro ejemplo de la intervención del legislador para garantizar la dimensión institucional de la libertad de información lo constituye el derecho de rectificación, dado que, mediante 
mensión institucional posibilita la plena eficacia de los derechos fundamentales en la vida social. Exige ciertas obligaciones positivas del Estado con el objeto de no sólo asegurar la libertad, sino también la igualdad de todos los ciudadanos en su ejercicio como, por ejemplo, tomando medidas que impidan la concentración de los medios de comunicación.

La evolución descrita sintéticamente también se hace patente tras el detenido estudio de las garantías específicas de las libertades de expresión e información en la Constitución española. Así, algunas garantías como, por ejemplo, la abolición de la censura previa o la interdicción del secuestro administrativo son de clara influencia liberal dado que tratan de preservar las libertades de expresión y de información frente a los poderes públicos. Y el derecho de acceso de los grupos sociales y políticos significativos a los medios de comunicación públicos y el control parlamentario de los mismos, junto con el derecho de rectificación (de creación legislativa) tienen por objeto asegurar el efectivo ejercicio de las libertades comunicativas y amparar la libre formación de la opinión pública, cuestión imprescindible para el funcionamiento del sistema democrático. Más en concreto, la Constitución española de 1978 se ha hecho eco de las experiencias del entorno constitucional en materia de libertades de expresión e información y ha incorporado a su texto positivo una serie de técnicas tendentes a asegurar el acceso de los grupos en que los ciudadanos se integran para el ejercicio de sus derechos con el objeto de que ejerzan sus libertades comunicativas y accedan efectivamente al mercado de las ideas las distintas corrientes de opinión de la sociedad ${ }^{15}$.

la regulación de este derecho, el Estado interviene en la libertad de expresión de los medios de comunicación para que el aludido por una noticia pueda publicar gratuitamente una versión diferente sobre los hechos trasmitidos por un medio de comunicación. De tal modo, que al publicarse dos versiones diferentes sobre unos mismos hechos, el público pueda formarse su opinión sobre la noticia. En este sentido, el Tribunal Constitucional en la STC 168/1986, de 22 de diciembre, FJ $5 .^{\circ}$, afirmó que: "el derecho de rectificación (...) supone (...) un complemento a la garantía de la opinión pública (...) ya que el acceso a una versión disidente de los hechos publicados favorece, más que perjudica, el interés colectivo en la búsqueda y recepción de la verdad».

15 En el derecho norteamericano se pretendió garantizar el acceso a los medios de comunicación a través de la fairness doctrine, que podría traducirse como la doctrina de la equidad. La fairness doctrine tiene como fin el ampliar y asegurar que todos los puntos de vista sean escuchados tanto en la radio como en la televisión. Sin embargo, la fairness doctrine fue parcialmente anulada por la FCC en 1987. Sobre la cuestión, entre otros, véanse RALLO LOMBARTE, A.: Pluralismo informativo y Constitución, Tirant lo Blanch, Valencia, 2000, p. 285, RODRÍGUEZ GARCÍA, J. A.: El control de los medios de comunicación, Dykinson, Madrid, 1998, p. 142.

En el derecho italiano el reconocimiento del derecho de acceso es de origen legislativo obligado, es decir, el legislador actuó en cumplimento de un famoso dictum de la Corte Costituzionale. Concretamente la sentencia de la Corte Contituzionale de 13 de julio de 1960, n. 59, en Giurisprudencia costitucionale 1960, 759; establece el derecho de acceso a los medios de comunicación públicos como condición de legitimidad del monopolio público de los medios de comunicación. Como consecuencia de la citada sentencia se dictó por el legislativo la Ley 103 de 14 de abril de 1975. Sobre la cuestión, entre otros, véanse BARILE, P.: Libertà de manifestazione del pensiero, Gruiffè editore, Milano, 1975, p. 67 y ss, CARETTI, P.: Diritto dell'informazione e della comunicazione. Spampa, radiotelevisioni, teatro e cinema, ob. cit., p. 91 y ss. 


\title{
III. EL ACCESO A LOS MEDIOS DE COMUNICACIÓN PÚBLICOS EN EL ORDENAMIENTO JURÍDICO ESPAÑOL
}

\author{
III.1. FundAMENTO Y NATURALEZA DEL ACCESO A LOS MEDIOS \\ DE COMUNICACIÓN PÚBLICOS
}

\section{A) El Fundamento del acceso a los medios de comunicación públicos}

En primer lugar se destacará, en plena sintonía con las consideraciones e interpretaciones que se han mantenido, que el derecho de acceso es una garantía de la dimensión objetiva o institucional de las libertades comunicativas y participa del mismo fundamento que aquéllas ${ }^{16}$. Esta dimensión institucional u objetiva de las libertades de expresión e información se corresponde con la garantía del instituto de la libre formación de la opinión pública que, a su vez, es una condición indispensable para el correcto funcionamiento del Estado democrático y del pluralismo político que le es inherente ${ }^{17}$. Como se ha señalado, para ejercer la libertad de expresión y sobre todo la de información, es imprescindible estar en posesión de unos medios materiales y económicos que sólo están al alcance de unos pocos. Esta situación genera que si bien estas libertades están reconocidas a todos los ciudadanos, no van a poder ser ejercidas efectivamente de manera igual, con lo que las opiniones de los que no poseen estos medios no podrán ser transmitidas para que sean escuchadas por todos. Sólo unos pocos podrán acceder al «libre mercado de las ideas" y la opinión pú-

Sobre el derecho de acceso a los medios en los tratados internacionales, entre otros, véanse POLO SABAU, J. R.: Libertad de expresión y el acceso a los medios de comunicación, Centro de Estudios Constitucionales, Madrid, 2002, p. 39 y ss, RODRÍGUEZ GARCÍA, J. A.: El control de los medios de comunicación, ob. cit., p 32 y ss.

16 Como alegan PARADA y BACIGALUPO, la Constitución española ha sido probablemente la primera dentro de los países del entorno constitucional que ha reconocido el derecho de acceso a los medios de comunicación dependientes del Estado. Pero, esta obligación no es sino una exigencia organizacional derivada de la dimensión jurídico-objetiva de las libertades de comunicación, que se haya reconocido, en mayor o menor medida, vía jurisprudencial o legislativa, en la práctica totalidad de los ordenamientos constitucionales. Respecto a su desarrollo jurisprudencial, los mencionados autores citan la sentencia de la sala $2 .^{\text {a }}$ del Tribunal Constitucional Federal alemán de 28 de febrero de 1961, relativa a la organización de la radio y a la televisión de titularidad pública. En la citada sentencia, el Tribunal Constitucional Federal alemán dedujo de la dimensión jurídico-objetiva de la libertad de radiodifusión, consagrada en el artículo 5.1 de la Ley Fundamental, un mandato al legislador para que éste asegure el pluralismo de la programación a través de la garantía de acceso a la radio y a la televisión pública de todos los grupos sociales y políticos relevantes. Véase PARADA VÁZQUEZ, R. y BACIGALUPO SAGGESE, M.: "El control parlamentario de los medios de comunicación del Estado", en ALZAGA VILLAMIL, O. (Dir.): Comentarios a la Constitución Española de 1978, tomo II, Edersa, Madrid, 1997, p. 562.

17 Como sostiene RALLO, la opinión pública libre, en cuanto institución política fundamental constituye una exigencia inherente a todo Estado democrático y, por lo tanto, las previsiones constitucionales y la acción de los poderes públicos deben interpretarse y adecuarse a la consecución de tal objetivo. Véase RALLO LOMBARTE, A.: Pluralismo informativo y Constitución, ob. cit., p. 64. 
blica resultante quedará viciada; las decisiones democráticas no serán las mejores para el autogobierno de los ciudadanos.

Para subsanar este efecto nocivo para el sistema democrático y como consecuencia de las trasformaciones de los derechos fundamentales en el Estado Social, mediante la intervención de los poderes públicos, en este caso garantizando el derecho de acceso "gratuito" al servicio público de radiotelevisión ${ }^{18}$, se pretende asegurar la participación de todos los ciudadanos en igualdad de condiciones en el proceso de la comunicación pública. Dicho de otro modo, el artículo 20.3 de la Constitución establece una garantía o si se quiere un instrumento, que posibilita el acceso de determinados grupos sociales y políticos a una plataforma (los medios de comunicación públicos) para la transmisión de sus mensajes. En definitiva, se busca que los derechos fundamentales sean ejercidos efectivamente por todos, esto es, se pretende la consecución efectiva de la libertad en igualdad ${ }^{19}$. Del mismo modo, mediante el acceso y de la consecuente posibilidad de contraste entre las distintas corrientes de opinión se garantiza la correcta formación de la opinión pública.

Sin embargo, el artículo 20.3 de la Constitución no se limita exclusivamente a reforzar la dimensión objetiva de las libertades comunicativas. Como apunta el Tribunal Constitucional, el artículo 20.3 impone «al legislador un mandato (la garantía de acceso a dichos medios de los grupos sociales y políticos significativos), que concede a esos grupos al menos el derecho a exigir que no se haga nada por impedir dicho acceso $\mathrm{O}^{20}$. Dicho de otro modo, al participar el articulo 20.3 de la misma naturaleza de las libertades de expresión e información, también participa de su doble naturaleza (subjetiva y objetiva o institucional). Con el matiz de que en el artículo 20.3 de la Constitución parece predominar la faceta objetiva sobre la subjetiva ${ }^{21}$.

Las anteriores afirmaciones no son óbice para sostener que el reconocimiento constitucional del acceso a los medios públicos también es uno de los instrumentos de garantía del pluralismo interno de los medios de comunicación

18 Téngase en cuenta que el derecho de acceso se predica exclusivamente de los medios de comunicación públicos, es decir, únicamente los medios — radio o televisión- que están sometidos a gestión pública — de la administración central, autonómica o local— deberán garantizar en sus respectivas programaciones, espacios para los grupos sociales y político. Respecto de los medios de titularidad privada no existe tal obligación, estos exclusivamente se regirán en su actividad por el régimen del ejercicio de las libertades de expresión e información reconocidas en el artículo 20.1 de la Constitución.

19 En este sentido, como afirma POLO SABAU, la imposibilidad de ejercicio de un derecho fundamental en el Estado social y democrático de Derecho equivale a su vaciamiento de contenido y, por tanto, a su misma negación en tanto que tal derecho fundamental. Véase POLO SABAU, J.R.: Libertad de expresión y el acceso a los medios de comunicación, ob. cit., p. 74 y ss.

20 Véase STC 6/1981, de 16 de marzo, FJ 5. En relación con la dimensión subjetiva, además del deber de los poderes públicos de no injerencia y no discriminación en el acceso a los medios de comunicación públicos, se considera que mediante este derecho se pretende poner de los medios materiales que posibiliten el libre desarrollo de su personalidad.

21 Véase PARADA VÁZQUEZ, R. y BACIGALUPO SAGGESE, M.: "El control parlamentario de los medios de comunicación del Estado", ob. cit., p. 561 y ss. 
públicos puesto que posibilita la manifestación de las opiniones de los distintos grupos ideológicos de la sociedad. En este sentido, como afirman los profesores Parada y Bacigalupo, eel pluralismo interno de los medios de comunicación de titularidad pública no es sino una exigencia organizacional derivada de la dimensión jurídico-objetiva de las libertades de comunicación consagradas en el artículo 20.1 de la Constitución, expresamente positivizada en el artículo 20.3 de la Constitución ${ }^{22}$ ".

\section{B) La naturaleza del acceso a los medios de comunicación}

En el artículo 20.3 de la Constitución, el poder constituyente ha realizado un mandato al legislador para que asegure el derecho de acceso a los medios de comunicación públicos de los grupos sociales y políticos significativos. La doctrina se ha planteado cuál es la naturaleza del aludido mandato, es decir, cuál es el ámbito material del que dispone el legislador a la hora de desarrollar el derecho de acceso a los medios de comunicación públicos. Más en concreto, la discusión se centra en si el artículo 20.3 de la Constitución constituye un derecho constitucional perfecto, un mero mandato programático al legislador o un derecho de configuración legal.

En primer lugar, se desechará la posibilidad de considerar el artículo 20.3 de la Constitución como un derecho fundamental perfecto y, en consecuencia, exigible directamente sin necesidad de desarrollo legislativo. El propio tenor literal del precepto, la ley "garantizará", lleva a desistir de realizar esta interpretación ${ }^{23}$.

Tampoco se está ante un mero mandato (objetivo) de características programáticas cuyo destinatario es el legislador. Sino que, como mantiene el propio Tribunal Constitucional, el artículo 20.3 de la Constitución reconoce un derecho de configuración legal, es decir, un derecho que deberá ser concretado por el legislador. Sin embargo, el legislador no es libre en la configuración del derecho de acceso, "ni la eventual vulneración de sus determinaciones por los aplicadores del Derecho podrá deducirse constitucionalmente irrelevante en orden al ejercicio eficaz de las libertades consagradas en el artículo $20^{24}{ }_{n}$. Por el contrario, la Constitución pretende que "por la ley se asegure a los grupos sociales y políticos significativos su acceso a los medios públicos ${ }^{25}$. Esta inter-

22 Véase PARADA VÁZQUEZ, R. y BACIGALUPO SAGGESE, M.: “El control parlamentario de los medios de comunicación del Estado", ob. cit. p. 561.

23 En contra de la opinión mantenida, GARCÍA TORRES Y JIMÉNEZ-BLANCO manifiestan que el citado artículo reconoce un derecho subjetivo sin necesidad de interpositio legislatoris, puesto que "se trata de un derecho fundamental reconocido por la Constitución e inmediatamente accionable con este carácter y no de un derecho de creación legislativa en cumplimiento de un mandato constitucional que no lo atribuye inmediatamente sino que sólo encarga al legislador su establecimiento". Véase GARCÍA TORRES, J. Y JIMÉNEZ-BLANCO, A.: Derechos fundamentales y relaciones entre particulares, Civitas, Madrid, 1986, p. 52.

24 Véase STC 63/1987, de 20 de mayo, FJ 6. ${ }^{\circ}$

25 Véase STC 63/1987, de 20 de mayo, FJ 7. 
pretación constitucional lleva a parte de la doctrina, al igual que el presente estudio, a mantener que el artículo 20.3 de la Constitución contiene un derecho parcialmente perfecto puesto que contiene elementos constitucionales previos, pero requiere también del desarrollo legal de determinados aspectos para asegurar la efectividad del derecho de acceso como, por ejemplo, delimitando el término grupos sociales significativos ${ }^{26}$.

\section{III.2. CONTENIDO DEL DERECHO DE ACCESO}

Como se acaba de aludir, el artículo 20.3 de la Constitución reconoce un derecho de configuración legal. En consecuencia, corresponde al legislador en exclusiva establecer el contenido de este derecho dentro de los márgenes establecidos en su reconocimiento constitucional, esto es, respetando sus líneas maestras.

Son varias las interpretaciones que ha suscitado el contenido del artículo 20.3 de la Constitución ${ }^{27}$. Pero, tanto del debate constituyente, de la doctrina

26 Véase RAllo lomBaRTe, A.: Pluralismo informativo y Constitución, ob. cit., p. 186. Asimismo, en este sentido, véase ROSADO IGLESIAS, G.: La televisión pública en España, régimen jurídico y control, Cedecs, Rubí, 1999, p. 243.

27 Sobre la cuestión, RALLO LOMBARTE resume las interpretaciones sobre el significado y contenido de este precepto constitucional en las siguientes:

a) El derecho de acceso como derecho a no impedir el acceso a los grupos sociales y políticos significativos. Esta explicación se fundamenta en los postulados de la STC 6/1981, de 16 de marzo, que estable que el artículo 20.3 impone al legislador un mandato "que concede a esos grupos al menos el derecho a exigir que no se haga nada para impedir dicho acceson. Esta afirmación sin posterior matización llevaría a concluir que este derecho estaría vacío de contenido y que, por ende, el Alto Tribunal apuesta por una interpretación exclusivamente liberal de la libertad de expresión. Pero, posteriormente matiza diciendo que: «la libertad de los medios de comunicación, sin la cual no sería posible el ejercicio eficaz de los derechos fundamentales que el artículo 20 de la Constitución enuncia, entraña seguramente la necesidad de que los poderes públicos, además de no estorbarla, adopten las medidas que estimen necesarias para remover los obstáculos que el libre juego de las fuerzas sociales pudieran oponerle. La cláusula del Estado social (artículo 1.1) y, en conexión con ella, el mandato genérico contenido en el artículo 9.2 imponen sin duda actuaciones positivas de este género."

b) El derecho de acceso como garantía institucional de la existencia de medios de comunicación social. En primer lugar, se debe aclarar que el término garantía institucional según esta interpretación, hace referencia a la garantía de la preservación del legislador, de la existencia los medios de comunicación del Estado en términos reconocibles. El magistrado Díez de Velasco, en el voto particular a la STC 86/1982, de 23 de diciembre, resume esta interpretación del modo siguiente: "el artículo 20, número 3, de la Constitución Española (CE) resulta infringido en tanto en cuanto el mismo va dirigido, entre otras cosas, a garantizar el acceso a los medios de comunicación social dependientes del Estado o de cualquier Ente público a los grupos sociales y políticos significativos respetando el pluralismo de la sociedad y de las diversas lenguas de España. Para respetar y facilitar la expresión de dicho pluralismo social es una "conditio sine qua non" la existencia de dichos medios de comunicación social, entre los cuales están, sin posibilidad de exclusión total, los medios de la prensa (...). La supresión total de referencia es contraria a la Constitución dados los términos del artículo 20 de la CE y en especial del número 3 del referido artículo, y ello porque del mismo se desprende la necesidad de garantizar a los grupos sociales y políticos significativos que 
constitucional y de su desarrollo legislativo, se desprende que el derecho de acceso se identifica con el derecho de los grupos sociales y políticos significativos a tiempos de antena gratuitos en las emisiones de los medios de comunicación públicos $^{28}$.

Así, respecto de la primera cuestión, la enorme similitud entre el artículo 20.3 de la Constitución y el artículo 40.1 de la Constitución de Portugal, en la redacción vigente durante el periodo constituyente español, parece avalar esta interpretación. Concretamente el citado precepto de la Constitución portuguesa prescribía que: "los partidos políticos y las organizaciones sindicales y profesionales tienen derecho a tiempos de antena en radio y televisión, de acuerdo a su representación y según criterios a definir en el estatuto de la información".

En lo referente a la jurisprudencia constitucional, la STC 63/1987, de 20 mayo, dictada con motivo de la distribución entre los grupos políticos de espacios gratuitos en la campaña del referéndum sobre la entrada en la OTAN, afirmó que: «aunque en el artículo 20.1.a) de la Constitución se enuncia un derecho de libertad que no exige, con carácter general, sino la abstención, la ausencia de trabas o impedimentos para su ejercicio, por parte de los poderes públicos (...), no es menos cierto que, en determinados casos, será necesaria la actuación positiva de los poderes públicos — del Legislador, específicamentepara la ordenación de los "medios" que sirvan de soporte a la expresión y difusión de ideas u opiniones, hipótesis ésta que, respecto de los medios de co-

no disponen de medios económicos u otros instrumentos para hacerse oír las vías necesarias para hacerlo". Pero, en realidad, como sostiene la jurisprudencia constitucional (STC 86/1982 y STC 63/1987) no hay una garantía institucional que protege la necesaria existencia de medios de comunicación dependientes del Estado. El artículo 20.3 de la Constitución sólo establece un mandato al legislador (en el caso de existir los citados medios) que consiste en asegurar que éstos deben someterse a determinadas reglas en su actuación que cercioren el acceso y control de todos en la formación de la opinión pública libre, "conditio sine qua non" del sistema democrático.

c) El derecho de acceso como derecho a participar en la designación de los miembros de los órganos de gobierno de los medios de comunicación públicos. No se participa de esta idea puesto que en esta designación no participan los grupos sociales significativos.

d) El derecho de acceso como derecho al control parlamentario de los medios de comunicación dependientes del Estado. Esta interpretación implicaría que el artículo 20.3 de la Constitución sería una mera reiteración constitucional puesto que, en general, la actividad de todos los poderes públicos queda sometida al control parlamentario. Y por otro lado, en esta interpretación quedarían excluidos en el control los grupos sociales más representativos.

e) El derecho de acceso como derecho a informar sobre los grupos sociales y políticos significativos. Según esta interpretación se trataría de no excluir en la actividad informativa de los medios públicos a los grupos sociales y políticos. No se puede compartir esta interpretación dado que la relevancia constitucional (artículos 6 y 7 CE) que poseen los citados grupos y la existencia de medios de comunicación privados impediría de facto silenciar su actuación. Véase RALLO LOMBARTE, A.: Pluralismo informativo y Constitución, ob. cit., p. 148 y ss.

28 En este sentido, véase RALLO LOMBARTE, A.: Pluralismo informativo y Constitución, ob. cit., 155 y ss. En sentido similar, LLAMAZARES CALZADILLA, define este derecho como ala facultad reconocida a los grupos sociales y políticos significativos de utilizar los medios de comunicación de titularidad pública para, en el ejercicio de sus libertades de expresión e información, transmitir y difundir sus ideas y doctrinas". Véase LLAMAZARES CALZADILLA, M. C.: Las libertades de Expresión e información como garantía del pluralismo político, Civitas, Madrid, p. 192 y ss. 
municación de titularidad pública, se halla expresamente contemplada en el artículo 20.3 de la misma Constitución, precepto que, en lo que importa ahora, impone que se garantice por la ley el derecho de acceso a dichos medios de los grupos sociales y políticos significativos, respetándose el pluralismo de la sociedad y de las diversas lenguas de España. No se prescribe en esta disposición, sin duda, la necesaria existencia de un sector público en el ámbito de la comunicación (...), pero sí se impone, contemplándose tal posibilidad, la exigencia que acaba de recordarse en orden al respeto al pluralismo social y político en el acceso a estos medios, con la consecuencia de que, existente el medio de titularidad pública y reglado su modo de utilización, habrá de reconocerse a los grupos sociales y políticos "significativos" a los que alude el precepto constitucional el derecho, cuando menos, a que no se les impida dicho acceso (...). Este derecho de acceso, en otras palabras, será en cada caso articulado por el Legislador, pero ni éste queda libre de todo límite constitucional en dicha configuración, ni la eventual vulneración de sus determinaciones por los aplicadores del Derecho podrá decirse constitucionalmente irrelevante en orden al ejercicio eficaz de las libertades consagradas en el artículo 20, pues estas libertades habrán de realizarse a través de estos medios, del modo que quiere la Constitución en el apartado 3 del mismo precepto, de tal modo que la denegación discriminatoria, o arbitraria por carente de fundamento legal, del acceso que la Ley haga posible, entrañará el consiguiente menoscabo del derecho del grupo así afectado - de quienes a su través pretendan difundir las propias ideas y opiniones- a la libertad que la Constitución garantiza [artículo 20.1.a) $]^{29}$,

Como sostiene el profesor Rallo Lombarte cuando analiza la sentencia reproducida arriba, eel Tribunal Constitucional ha reconocido que la democratización de la comunicación exige superar la lectura liberal que sustanciaba la efectividad de la libertad de información en la ausencia de trabas, impedimentos o restricciones derivadas de los poderes públicos y ha residenciado en éstos la garantía efectiva de su ejercicio, conminándoles a desarrollar las actuaciones positivas que se requieran ${ }^{30}$.

Por último, las distintas normas que desarrollan el artículo 20.3 de la Constitución también avalan la interpretación mantenida. Así, el artículo 8.1 de la Ley 4/1980, por la que se regula el Estatuto de Radio y la Televisión (en adelante, ERTV), prescribe que el Consejo de Administración de Radiotelevisión española es competente para determinar semestralmente el porcentaje de horas de programación destinadas a los grupos políticos y sociales significativos, fijando los criterios de distribución entre ellos en cumplimiento de lo establecido en el artículo 20 de la Constitución. Para realizar esta labor, el Consejo de Administración, de acuerdo con el Director General, en el ejercicio de sus respectivas competencias, tendrán en cuenta criterios objetivos tales como representación

29 Véase STC 63/1987, de 20 mayo, FJ 6. ${ }^{\circ}$

30 Véase RALLO LOMBARTE, A.: Pluralismo informativo y Constitución, ob. cit., p. 159. 
parlamentaria, implantación sindical, ámbito territorial de actuación y otros similares $^{31}$. Las normas reguladoras de las distintas televisiones autonómicas desarrollan el derecho de acceso de manera prácticamente idéntica ${ }^{32}$. Del mismo modo, las normas ordenadoras del proceso electoral y de referéndum concretan el derecho de acceso atribuyendo espacios gratuitos de propaganda en las emisoras de televisión y radio de titularidad pública a los partidos políticos, federaciones y coaliciones electorales ${ }^{33}$.

\section{III.3. Titularidad y DeSARROllo LEgislativo}

El legislador a la hora de desarrollar el contenido del artículo 20.3 de la Constitución debe determinar esencialmente dos cuestiones. En primer lugar, cuáles son los grupos políticos y sociales a los que hace referencia el citado precepto constitucional respetando el pluralismo político, social y lingüístico de la sociedad española y, por extensión, tiene que fijar qué grupos sociales o políticos son los que se consideran significativos, puesto que el citado precepto establece un mandato al legislador que consiste en asegurar el acceso a los grupos (no personas o sujetos individuales) que se consideren significativos. En segundo lugar, el legislador debe articular el ejercicio del acceso, es decir, debe determinar cuestiones como, por ejemplo, los requisitos formales y materiales que deben cumplir los grupos sociales y políticos significativos, los órganos administrativos encargados de hacer efectivo el ejercicio del acceso, los tiempos y horarios de antena gratuitos en los medios de comunicación públicos, etc.

Del articulado de la Constitución se desprenden varios ejemplos de cuáles son los grupos sociales y políticos significativos. Así, el articulo 6 establece que los partidos políticos «expresan el pluralismo político, concurren a la formación y manifestación de la voluntad popular y son instrumento fundamental para la participación política". El artículo 7 dispone que "los sindicatos de trabajadores y las asociaciones empresariales contribuyen a la defensa y promoción de los intereses económicos y sociales que les son propios", el artículo 16 alude a las

31 Véase artículo 24 de la Ley 4/1980 de 10 de enero, de Estatuto de la Radio y Televisión.

32 Véase artículos 6.1 k) y 16 de la Ley 13/1984, de 30 de junio, de creación, organización y control de Radio Televisión Madrid, artículo 21 de la Ley $7 / 1984$, de julio, de creación de la entidad pública radio televisión valenciana y regulación de los servicios de radio difusión y televisión de la Generalidad Valenciana, artículo 21.2 de la Ley 5/1982, de 20 de mayo, de creación del Ente público "Radio Televisión Vasca", artículo 6.1 k) y el artículo 18 de la ley 8/1987, de 9 de diciembre, de creación de la empresa pública de la radio y Televisión gestionados por la Junta de Andalucía, artículos 7.1 ll) y 17.1 de la Ley 9/1984, de 11 de julio, de creación de radiotelevisión de Galicia, artículo 7.1 k) y 17 Ley 7/1985, de 22 de mayo, de creación de la radiotelevisión de las Islas Baleares. En el ámbito de la radio difusión véase el artículo 8.1 y el artículo 19, de la Ley 7/1984, de 17 de noviembre, de Extinción de Radio Televisión Murciana, regulación del servicio público de radiodifusión y creación como empresa pública de Onda Regional de Murcia.

33 Véase artículo 60.2 de la LOREG y el artículo 14 de la Ley Orgánica 2/1980, de 18 de enero, de regulación de las distintas modalidades de Referéndum. 
comunidades religiosas, el artículo 51 hace referencia a las asociaciones de usuarios y consumidores, etc.

En la actualidad no existe una norma que desarrolle el derecho de acceso a los medios de comunicación dependientes del Estado de manera específica. En cambio, las normativas organizadoras de los medios de comunicación públicos y algunas normas sectoriales ${ }^{34}$, desarrollan parcialmente el derecho de acceso reconocido en el artículo 20.3 de la Constitución ${ }^{35}$. Respecto a las normativas organizadoras de los medios de comunicación públicos, el artículo 24 del ERTV, que forma parte de la sección tercera denominada "pluralismo democrático y derecho de acceso", establece como criterios objetivos para determinar cuales son estos grupos, la representación parlamentaria, la implantación sindical o el ámbito territorial de actuación. Las normas de los distintos canales de televisión autonómicos añaden otros criterios como, por ejemplo, la implantación social o la representación patronal. En cualquier caso, se considera necesario que los grupos sociales y políticos significativos estén válidamente constituidos y posean personalidad jurídica.

\section{III.4.1. El derecho de acceso de los grupos políticos más significativos}

No existe gran dificultad para determinar cuáles son los grupos políticos que menciona el artículo 20.3 de la Constitución, puesto que acudiendo al artículo 6 de la misma, se llega a la conclusión de que se refiere a los partidos políticos. Dentro de esta denominación también se incluyen, tal y como prescribe el artículo 60 de la Ley Orgánica del Régimen Electoral General (en adelante,

34 En el ámbito nacional, véanse Ley 4/1980, de 10 de enero, por la que se aprueba el Estatuto de Radio y Televisión, modificada por la Ley Orgánica 2/1984, de 26 de marzo; Ley 31/1987, de 18 de diciembre y Ley $11 / 1998$, de 24 de abril; y la ley $24 / 2001$, de 27 de diciembre. En el ámbito autonómico desarrollan parcialmente el derecho de acceso además de las leyes anteriormente citadas, artículo $6.1 \mathrm{k}$ ) y el artículo 18 de la ley 8/1987, de 9 de diciembre, de Andalucía; el artículo 7 y 17 de la Ley 9/1984, de 11 de julio, de Galicia, Ley 7/1985, de 22 de mayo, de radiotelevisión de las Islas Baleares.

Respecto de las citadas normativas sectoriales, sobre el periodo electoral o la celebración de referéndum, véase Ley Orgánica 5/1985, de 19 de junio, del régimen electoral general, modificada parcialmente por entre otras la Ley Orgánica 8/1991, de 13 de marzo; Ley Orgánica 2/1988, de 3 de mayo, reguladora de la publicidad electoral en las emisoras de televisión privada; Ley Orgánica 10/1991, de 8 de abril, de publicidad electoral en emisoras municipales de radiodifusión sonora y Ley Orgánica 2/1980, de 18 de enero, reguladora de las distintas modalidades de Referéndum. En materia de consumidores y usuarios, véase el artículo 17 de la Ley 26/1984, de 19 de julio, de consumidores y usuarios.

35 La situación descrita ha llevado a parte de la doctrina a afirmar que la ordenación legal del derecho de acceso tiene un carácter dual. Así, por un lado, se estable un régimen general para todos los grupos significativos y, de otro, se regula un régimen especial para los grupos políticos durante la campaña electoral o durante la campaña de un referéndum. Como consecuencia de lo anterior, la normativa de régimen especial se regula mediante Ley Orgánica y la general mediante Ley ordinaria. Véase LLAMAZARES CALZADILLA, M. C.: Las libertades de Expresión e información como garantía del pluralismo político, ob. cit., p. 197 y ss. 
LOREG), las federaciones, coaliciones o agrupaciones de partidos que se presenten a las elecciones.

Las normativas sectoriales regulan el derecho de acceso de los grupos políticos según determinadas circunstancias, que son:

\section{A) El derecho de acceso durante el periodo de la campaña electoral}

Antes de estudiar la legislación electoral se deben destacar dos cuestiones que resultan relevantes para su exposición ${ }^{36}$. En primer lugar, durante el periodo de los comicios electorales es cuando más se estrecha la conexión entre las libertades de expresión e información con el sistema democrático y representativo. Así, en el actual parlamentarismo, las campañas electorales se realizan fundamentalmente a través de los medios de comunicación de masas ${ }^{37}$. En las elecciones se "oficializa" la opinión pública y se determina la composición de los órganos estatales. En segundo lugar, y como consecuencia de lo anterior, además de asegurase el derecho de acceso para que todos sean escuchados, se debe garantizar la equidad durante el periodo de competencia electoral ${ }^{38}$. En definitiva, se debe posibilitar una auténtica concurrencia, presentación y discusión de las distintas opciones ante los ciudadanos, hay que garantizar a las distintas opciones políticas una igualdad de oportunidades real y efectiva ${ }^{39}$. La citada igualdad de oportunidades debe ser entendida como igualdad entre iguales y desigualdad entre los desiguales. Por lo que, como se observará posteriormente, el tiempo de propaganda electoral se distribuye conforme a dos

36 Sobre la publicidad y conducta electoral en las modernas democracias, entre otros, véanse HABERMAS, J.: Historia y crítica de la opinión pública, E. Gustavo Gili, México, 1986, p. 237 y ss, SARTORI, G.: Teoría de la Democracia. 1. El debate contemporáneo, Alianza, Madrid, 2000, p. 126 y ss, ARNALDO ALCUBILLA, E.: "Procesos electorales y opinión pública", Revista de las Cortes Generales, núm. 34,1995, p. 173 y ss, MONZÓN ARRIBAS, C.: Opinión pública, comunicación y política. La formación del espacio público, Tecnos, Madrid, 1996, 298 y ss.

37 Sobre evolución de las relaciones entre la opinión pública y el Parlamento, véase MUÑOZALONSO, A.: "Opinión pública y Parlamento (Las transformaciones del régimen parlamentario)", Revista de las Cortes Generales, núm. 35, p. 8 y ss.

38 Sobre el principio de concurrencia como eje de la ordenación jurídica del proceso electoral, véase SOLOZÁBAL ECHAVARRÍA, J. J.: «Una visión institucional del proceso electoral", Revista Española de Derecho Constitucional, núm. 39, 1993, p. 65 y ss.

39 Téngase en cuenta que la legislación electoral también prescribe respecto de los medios de comunicación públicos otros principios como: a) La obligación de respeto al pluralismo político y social y la neutralidad informativa (artículo 66 LOREG). b) La prohibición de contratar espacios de publicidad electoral en los medios de comunicación públicos (artículo 60.1 LOREG). Por otro lado, en relación con los medios de comunicación privados, la LO 2/1988, de 3 de mayo, de reguladora de la publicidad electoral en las emisoras de televisión privada, establece la garantía del respeto al pluralismo y a los valores de igualdad en los programas difundidos durante la campaña electoral por las emisoras de televisión privada y que estarán garantizados por las Juntas Electorales Centrales en los términos previstos por la legislación electoral para los medios de comunicación de titularidad pública. Asimismo establece la prohibición de contratar publicidad en las emisoras de televisión privada con el fin de preservar la equidad o la igualdad material. 
criterios, uno de igualdad mínima con el objeto de asegurar que todos sean escuchados y tengan las mismas oportunidades, y otro variable, que se atribuirá proporcionalmente según la representación parlamentaria obtenida en las anteriores elecciones equivalentes. En virtud de lo anterior, cobra sentido la idea de servicio público, en lo que ahora toca de radiotelevisión, como mecanismo que garantiza el igual ejercicio de los derechos fundamentales, en este caso posibilitando el acceso de los distintos grupos a los medios materiales que faciliten la transmisión de sus ideas ${ }^{40}$.

El derecho de acceso de los grupos políticos reconocido en el artículo 20.3 de la Constitución se especifica durante la campaña electoral en el derecho a espacios gratuitos de propaganda en las emisoras de televisión y radio de titularidad pública ${ }^{41}$.

De la legislación electoral estatal se enunciarán tres cuestiones, que son: los criterios de asignación de los espacios gratuitos, los órganos encargados de distribuirlo y su contenido ${ }^{42}$.

40 Sobre la cuestión, véase CHINCHILLA MARÍN, C.: La radiotelevisión como servicio público esencial, Tecnos, Madrid, 1988, p. 103 y ss. Asimismo la exposición de motivos de la Ley 4/1980, de 10 de enero, por la que se aprueba el ERTV, también se incide en esta misma idea del siguiente modo: "La radiodifusión y la televisión, configuradas como servicio público esencial, cuya titularidad corresponde al Estado, se concibe como vehículo esencial de información y participación política de los ciudadanos, de formación de la opinión pública, de cooperación con el sistema educativo, de difusión de la cultura española y de sus nacionalidades y regiones, así como medio capital para contribuir a que la libertad y la igualdad sean reales y efectivas, con especial atención a la protección de los marginados y a la no discriminación de la mujer".

$41 \mathrm{El}$ artículo 50.2 de la LOREG define la campaña electoral como "el conjunto de actividades lícitas llevadas a cabo por los candidatos, partidos, federaciones, coaliciones o agrupaciones en orden a la captación de sufragios". La aludida campaña tiene una duración de 15 días tras lo que no se puede realizar ningún tipo de propaganda electoral.

42 La regulación de las normas electorales de las distintas Comunidades Autónomas es semejante a establecida en la LOREG. Sobre la cuestión, véanse Ley 1/1986, de 2 de mayo, electoral de Andalucía; Ley 2/1987, de 16 de febrero, electoral de la comunidad autónoma de Aragón (modificada por la Ley 4/1991, de 20 de marzo, por la Ley 4/1992, de 17 de marzo, por la Ley 3/1995, de 29 de marzo, por la Ley 13/1997, de 15 de diciembre, y por la Ley 10/1999, de 14 de abril); Ley 3/1987, de 27 de marzo de medidas urgentes en materia electoral de Canarias (modificada por la Ley 2/1991, de 18 de marzo, y por la Ley 5/1995, de 1 de abril); Ley de 5/1987, de 27 de marzo, de elecciones al Parlamento de Cantabria (modificada por Ley 4/1991, de 22 de marzo, por la Ley 6/1999, de 24 de marzo y por la Ley 1/2000, de 24 de mayo); Ley 5/1986, de 23 de diciembre, electoral de Castilla-La Mancha (modificada por Ley 5/1990, de 26 de diciembre, de presupuestos generales de Castilla-La Mancha para 1991, por la Ley 1/1991, de 15 de marzo, por la Ley 5/1994, de 16 de diciembre, de presupuestos generales de Castilla-La mancha para 1995 y por la Ley 8/1998, de 19 de noviembre); Ley 3/1987, de 30 de marzo, electoral de Castilla León (modificada por la Ley 4/1991, de 20 de marzo); Ley 8/1986, de 26 de noviembre, de la Comunidad Autónoma de las Islas Baleares (en su redacción dada por la ley 4/1995, de 21 de marzo, por La ley 5/1995, de 22 de marzo, por La ley 9/1997, de 22 de diciembre y por la Ley 6/2002, de 21 de junio); Ley 11/1986, de 16 de diciembre, electoral de la Comunidad de Madrid (modificada por la Ley 4/1991, de 21 de marzo, por la Ley 5/1995, de 28 de marzo, por la Ley 15/1995, de 21 de abril, por la Ley 12/1998, de 9 de julio y por la Ley 12/2003, de 26 de agosto); Ley Foral 16/1986, de 17 de noviembre, reguladora de las elecciones al Parlamento de Navarra (modificada por Ley Foral 11/1991, de 16 de marzo y por Ley Foral 13/1998, de 6 de octubre); Ley 1/1987, de 31 de marzo, electoral valenciana; Ley 2/1987, de 16 de marzo, de elecciones a la Asamblea de Extremadura (modificada por la Ley 2/1991, de 21 
La distribución de los espacios electorales gratuitos se realiza conforme a dos criterios:

1. Uno de igualdad mínima para los partidos, federaciones y coaliciones de electores que no concurrieron — de nueva creación- o que no obtuvieron representación en las anteriores elecciones equivalentes.

2. ${ }^{\circ}$ Otro proporcional, que atiende al número de votos obtenidos en las anteriores elecciones y al número de circunscripciones en que cada partido presenta candidaturas ${ }^{43}$.

Además, el artículo 64.2 de la LOREG prevé que el derecho de acceso corresponderá únicamente a los partidos, federaciones o coaliciones que presenten candidaturas en más del 75 por 100 de las circunscripciones comprendidas en el ámbito de cobertura del medio de comunicación correspondiente ${ }^{44}$.

La distribución de los espacios gratuitos se efectúa por la Junta Electoral Central. Con el objeto de realizar la propuesta de la citada distribución se constituye la Comisión de Radio y Televisión que, a su vez, actúa bajo la direc-

de marzo); Ley 8/1985, de 13 de agosto, de elecciones al Parlamento de Galicia (modificada por la Ley 15/1992, de 30 de diciembre), Ley del Principado 14/1986, de 26 de diciembre, sobre el régimen de elecciones a la Junta General Principado (modificada por la Ley 3/1991, de 25 de marzo); Ley 2/1987, de 24 de febrero, electoral de la Región de Murcia (modificada por la Ley 1/1991, de 13 de marzo y por la Ley 9/1995, de 24 de abril); Ley 3/1991, de 21 de marzo, de elecciones a la Diputación General de la Rioja; Ley 5/1990, de 15 de junio, de elecciones al Parlamento Vasco (modificada por la Ley 15/1998, de 19 de junio y por la Ley 6/2000, de 4 de octubre; y Ley 5/1984, de 5 de marzo, por la que se adapta la normativa general electoral para las elecciones del Parlamento de Cataluña.

43 El artículo 64 de la LOREG distribuye el tiempo gratuito de espacios de propaganda electoral entre los grupos con representación en las anteriores elecciones de la siguiente manera: $₫ \mathrm{~b}$ ) Quince minutos para los partidos, federaciones y coaliciones que habiendo obtenido representación en las anteriores elecciones equivalentes, no hubieran alcanzado el 5 por 100 del total de votos válidos emitidos en el territorio nacional o, en su caso, en las circunscripciones a que hace referencia el artículo 62. c) Treinta minutos para los partidos, federaciones y coaliciones que habiendo obtenido representación en las anteriores elecciones equivalentes, hubieran alcanzado entre el $5 \mathrm{y}$ el 20 por 100 del total de votos a que se hace referencia en el párrafo b). d) Cuarenta y cinco minutos para los partidos, federaciones y coaliciones que habiendo obtenido representación en las anteriores elecciones equivalentes, hubieran alcanzado, al menos un 20 por 100 del total de votos a que hace referencia el párrafo b)".

44 Para atenuarlos efectos de este requisito, los apartados tercero y cuarto del mismo artículo regulan las siguientes posibilidades: «3. Los partidos, asociaciones, federaciones o coaliciones que no cumplan el requisito de presentación de candidaturas establecido en el apartado anterior tienen, sin embargo, derecho a quince minutos de emisión en la programación general de los medios nacionales si hubieran obtenido en las anteriores elecciones equivalentes el 20 por 100 de los votos emitidos en el ámbito de una Comunidad Autónoma en condiciones horarias similares a las que se acuerden para las emisiones de los partidos, federaciones y coaliciones a que se refiere el apartado 1.d) de este artículo. En tal caso la emisión se circunscribirá al ámbito territorial de dicha Comunidad. Este derecho no es acumulable al que prevé el apartado anterior. 4. Las agrupaciones de electores que se federen para realizar propaganda en los medios de titularidad pública, tendrán derecho a diez minutos de emisión, si cumplen el requisito de presentación de candidaturas exigido en el apartado 2 de este artículo". 
ción de la primera. La citada comisión está integrada por un representante de cada partido, federación o coalición con representación en el Congreso de los Diputados y toma sus decisiones mediante votación ponderada de acuerdo con la composición de la mencionada Cámara. Para la distribución de espacios gratuitos en las programaciones regionales y locales de los medios de comunicación del Estado y aquellos otros de ámbito similar, se prevé la posibilidad de delegar las atribuciones de la Junta Electoral Central en las Juntas Electorales provinciales. A su vez, para la citada distribución se constituirá una Comisión con las mismas potestades y con una composición que tendrá en cuenta la representación parlamentaria en el Congreso de los Diputados en el ámbito territorial respectivo.

Para la determinación del momento y orden de emisión de los espacios de propaganda electoral, la Junta Electoral tendrá en cuenta las preferencias de los partidos políticos, federaciones o coaliciones electorales, en función del número de votos que obtuvieron en las anteriores elecciones equivalentes.

Respecto del contenido de los mensajes transmitidos en los espacios electorales, no existe ninguna disposición que imponga alguna limitación, esto es, el contenido de los citados espacios queda a la libre disposición de los grupos políticos. En cualquier caso, los mensajes electorales están sometidos a las limitaciones de las libertades de expresión e información establecidas en el artículo 20 de la Constitución. En este sentido, se debe tener en cuenta que el Tribunal Constitucional afirmó en la STC 136/1999, de 20 de julio, que "en el ámbito de los procesos electorales, sólo en los casos muy extremos cabrá admitir la posibilidad de que un mensaje tenga la capacidad suficiente para forzar o desviar la voluntad de los electores, dado el carácter íntimo de la decisión del voto y los medios existentes para garantizar la libertad del sufragio ${ }^{45}$ ".

45 La cuestión del contenido y limitaciones en la utilización de los espacios gratuitos de propaganda electoral fue estudiada en la STC 136/1999, de 20 de julio, "Caso mesa nacional de HB". Los hechos fueron los siguientes, la mesa nacional de HB acordó difundir en los espacios gratuitos de propaganda electoral un spot publicitario y una cinta magnetofónica que contenía la denominada "alternativa democrática", previamente remitidos por la organización terrorista ETA. En el mencionado acuerdo también se asumió como propio el contenido tanto del spot como de la cinta magnetofónica. El spot televisivo se inicia con unas palabras previas de $\mathrm{HB}$ en las que se afirma que se cede la palabra a los que realmente ofrecen una "alternativa para la paz y para la democracia". Tras el discurso, aparecen tres hombres encapuchados sentados detrás de una mesa mostrando sus pistolas y el anagrama de ETA. Los tres presuntos terroristas afirmaron que sólo en el caso de cumplirse sus exigencias anunciarían un alto el fuego. Detrás ellos aparece un cartel que dice "Vota Herri Batasuna". En la cinta magnetofónica que el área de comunicación de HB remitió a Radio Nacional de España para que lo insertara en los espacios gratuitos de la campaña electoral, tras exponer la coalición política sus objetivos se concluye que "ETA manifiesta que cesará su actividad armada cuando se consigan y garanticen los citados contenidos mediante un acuerdo político". Tras lo que se pide el voto. Parece claro que, ni los derechos de participación ni las libertades comunicativas - siendo una manifestación de éstas el derecho de acceso- no protegen «la difusión de programas o mensajes que por su contenido, debidamente contextualizado, resulten amenazantes o intimidatorios, especialmente cuando esos efectos se producen durante los procesos electorales como consecuencia de la difusión de mensajes que pretenden decantar el sentido del voto hacia las opciones mantenidas por quienes las transmiten por temor a sufrir daños o perjuicios" (FJ 14..$^{\circ}$ ). El 


\section{B) El derecho de acceso durante el periodo de referéndum}

En el proceso de racionalización del parlamentarismo, que se originó aproximadamente durante el periodo de entreguerras y con la aparición de los grandes partidos de masas, se reconoció, por primera vez, la posibilidad del referéndum con la finalidad de incrementar la participación de los ciudadanos y de solventar los problemas que generaba la ficción legal de que en el Parlamento reside la voluntad popular ${ }^{46}$. Dicho de otro modo, mediante el referéndum se trató de buscar una vía de conexión entre el Parlamento y la opinión pública.

La Constitución de 1978 reconoce varias modalidades de consulta popular. Para todas ellas, el artículo 14 de la Ley Orgánica 2/1980, de 18 de enero, de regulación de las distintas modalidades de referéndum (en adelante, LOR), establece que durante la campaña de propaganda, los medios de difusión de titularidad pública deberán conceder espacios gratuitos a los grupos políticos con representación institucional. Se está en definitiva, ante una segunda concreción del derecho de acceso a los medios de comunicación públicos de los grupos políticos significativos.

La LOR regula dos supuestos para la concesión de espacios gratuitos de publicidad durante la campaña previa a la celebración de un referéndum:

1. En el caso de que la consulta se extienda a todo el territorio nacional, se concederán espacios de propaganda de idéntico alcance a los grupos políticos con representación en las Cortes Generales en proporción a la misma.

2. ${ }^{\circ}$ En las restantes modalidades de referéndum, los espacios se concederán en emisiones, en horas de gran audiencia, o publicaciones que cubran las provincias en las que se celebre el referéndum. En este caso, la distribución se realizará conforme a la representación obtenida en el Congreso de los Diputados en el ámbito territorial donde se convoque la consulta popular, en la asamblea legislativa de la Comunidad Autónoma o, en defecto de ésta, en cualquiera de las Diputaciones provinciales comprendidas en el ámbito territorial a que afecte el referéndum.

Sobre la regulación descrita, llama poderosamente la atención la notable disminución del derecho de acceso en comparación con el periodo de campaña electoral. Sólo se reconoce a los grupos políticos significativos que tengan representación institucional en el ámbito territorial donde se realiza la consulta.

Estado debe asegurar que el debate público sea libre y vigoroso y, por lo tanto, evitar que se transmitan "mensajes que incorporen amenazas o intimidaciones a los ciudadanos o a los electores". Si el órgano gestor del medio de comunicación en el que se intenta insertar la publicidad considera delictivo su contenido, lo deberá poner inmediatamente en conocimiento de las autoridades judiciales, que a tenor de lo establecido en el artículo 20.5 de la Constitución podrán acordar su secuestro mediante resolución judicial.

46 Véase MUÑOZ-ALONSO, A.: “Opinión pública y Parlamento (Las transformaciones del régimen parlamentario)", ob. cit., p. 46 y ss. 
Según la perspectiva mantenida en el presente estudio, el acceso a los medios de comunicación durante la campaña de referéndum se debería homogeneizar con el establecido para la campaña electoral.

\section{C) El derecho de acceso durante la programación ordinaria de los medios de comunicación públicos}

Resta por estudiar el acceso de los grupos políticos significativos durante los periodos en los que no existe campaña electoral ni consulta popular, es decir, durante las emisiones ordinarias de los medios de comunicación públicos.

Las normas reguladoras de los medios de comunicación públicos apenas desarrollan el derecho de acceso de los grupos políticos significativos reconocido en el artículo 20.3 de la Constitución durante su programación ordinaria. De las escasas referencias legislativas, se puede destacar que entre las competencias del Consejo de Administración de RTVE se encuentra la facultad de determinar semestralmente el porcentaje de horas de programación destinadas a los grupos políticos significativos. También se hace referencia a que la disposición de los espacios se concretará de modo que accedan a estos medios de comunicación los grupos políticos significativos teniendo en cuenta su representación parlamentaria. La legislación autonómica —en sus respectivos ámbitos- establece que también se deberá tener en cuenta como criterio objetivo su implantación política ${ }^{47}$, su representación en los Territorios Históricos o en los ayuntamientos de la Comunidad Autónoma ${ }^{48}$.

La escasa concreción legislativa observada y la atribución de la competencia a un órgano administrativo, han llevado a la práctica inaplicación del derecho de acceso de los grupos políticos durante las emisiones ordinarias, con la consecuente merma en la formación de la opinión pública.

\section{III.4.2. El derecho de acceso de los grupos sociales significativos}

El artículo 20.3 de la Constitución también prescribe que la ley garantizará el acceso a los grupos sociales significativos. Como se ha aludido, parece claro que en principio quedarán comprendidos dentro de este ámbito, los sindicatos, las organizaciones empresariales, los grupos religiosos, las asociaciones de consumidores y usuarios, etc.

Para el estudio de esta cuestión se realizará referencia casi exclusiva a su desarrollo en las normativas reguladoras de los distintos medios de comunica-

47 En este sentido, véanse artículo 17.1 de la Ley 9/1984, de 11 de julio, de creación de radiotelevisión de Galicia y artículo 17.1 de Ley 7/1985, de 22 de mayo, de creación de la radiotelevisión de las Islas Baleares.

48 Véase artículo 21 de la Ley 5/1982, de 20 de mayo, de creación del Ente público "Radio Televisión Vasca". 
ción públicos, dado que ni la LOREG ni la LOR reconocen el derecho de acceso de los citados grupos durante el periodo electoral o de consulta popular. Así, de manera idéntica a la que se reconoce a los grupos políticos durante la programación ordinaria, el artículo 24 del ERTV, que como se aludió se encuentra ubicado bajo la rúbrica "pluralismo democrático y acceso a los medios de comunicación", establece que la disposición de los espacios en RNE y TVE se concretará de modo que accedan los grupos sociales significativos. A tal fin, el Consejo de Administración, de acuerdo con el Director General, tendrán en cuenta criterios objetivos tales como la implantación sindical, el ámbito territorial u otros similares. Como se observa, la legislación que desarrolla el derecho de acceso no determina de forma clara y taxativa cuáles son los grupos sociales significativos, esto es, el legislador, tanto estatal como autonómico, únicamente se limita a establecer varios ejemplos para determinar cuáles son los grupos significativos. La situación descrita no impide que se reconozcan a otros grupos el carácter de significativo, sobre todo teniendo en cuenta la posible aparición de otros grupos nuevos.

Asimismo llama poderosamente la atención que las leyes reguladoras de los distintos medios de comunicación públicos no contemplan un procedimiento con las garantías debidas que posibilite el ejercicio del derecho de acceso. Por lo tanto, corresponde en exclusiva a los Consejos de Administración de acuerdo con los Directores Generales de los medios determinar trimestralmente el tiempo de antena del que disponen. Como se observa, existe una enorme discrecionalidad para los órganos gestores de los medios de comunicación públicos, únicamente limitada por la prohibición de discriminación y de arbitrariedad.

En relación con los consumidores y usuarios, el artículo 17 de la Ley 26/1984, de 19 de julio, estableció que los medios de comunicación públicos dedicarían espacios y programas no publicitarios a las asociaciones de consumidores, y facilitarían su acceso a los aludidos medios. Sin embargo, esta previsión legal no ha sido desarrollada y, al igual que los anteriores grupos sociales, su acceso no se ha materializado.

Respecto al tiempo de antena de los grupos religiosos, si bien parece evidente que dentro de la categoría de grupos sociales significativos se encuentran las confesiones religiosas, y entre ellas la católica, las disposiciones reguladoras de los distintos medios de comunicación públicos no las mencionan de manera expresa. Por razones de significación y sistemáticas, se estudiará separadamente el reconocimiento del derecho de acceso de la Iglesia Católica del resto de las confesiones religiosas o religiones acatólicas ${ }^{49}$.

1. ${ }^{\circ}$ La Iglesia católica, incluso antes de aprobar el ERTV, ya disponía varios espacios de emisión durante la programación ordinaria. Tras la aprobación del ci-

49 Para profundizar más sobre la cuestión, entre otros, véanse ROSELL, J.: Confesiones religiosas y medios de comunicación, ob. cit., p. 67 y ss, RODRÍGUEZ GARCÍA, J. A.: El control de los medios de comunicación, ob. cit., p. 233 y ss, POLO SABAU, J.R.: Libertad de expresión y el acceso a los medios de comunicación, ob. cit., p. 122 y ss. 
tado Estatuto, el Consejo de Administración de RTVE promulgó los "principios básicos de programación" que fundamentaron la emisión de programas religiosos católicos en el principio constitucional de libertad religiosa y de culto, las relaciones de cooperación de los poderes públicos con las distintas confesiones y el hecho sociológico de la práctica mayoritariamente católica de la población ${ }^{50}$.

Parte de la doctrina considera que el apartado XIV del Acuerdo sobre educación y asuntos culturales firmado entre el Estado español y la Santa Sede, reconoce implícitamente el derecho de acceso ${ }^{51}$. Siguiendo esta interpretación, el derecho de acceso se debería concretar mediante la firma de un acuerdo entre ambos sujetos. Sin embargo, en la práctica, este artículo sólo ha servido de apoyo legal para la firma de varios convenios con diversos entes públicos de radiotelevisión autonómicos ${ }^{52}$.

2. ${ }^{\circ}$ Con relación al resto de las confesiones religiosas, en el citado acuerdo de 1981, por el que se establecieron los "principios básicos de programación", se dispuso la posibilidad de abrir la programación a otras confesiones religiosas teniendo en cuenta su peso social, esto es, su número de fieles. Para valorar la "Significación" de las distintas confesiones religiosas, el Consejo de Administración de RTVE solicitó un informe a la Comisión asesora de libertad religiosa. Ésta tras afirmar que no se debe confundir el notorio arraigo, al que se refiere el artículo 7.1 de la Ley Orgánica de Libertad Religiosa, con el de grupos significativos, y declarar que existen otros criterios para determinar su significación, enunció a modo de ejemplo como grupos religiosos significativos la confesión evangélica, la israelita y la islámica ${ }^{33}$.

Como se observa, el derecho de acceso de los citados grupos religiosos se ha concretado, de acuerdo con la interpretación que se ha efectuado del artículo 20.3 de la Constitución, en la concesión de espacios de televisión o tiempos de antena en los medios de comunicación públicos. El tiempo de antena se determina en virtud de la implantación de la confesión religiosa y la programación será responsabilidad del grupo religioso.

50 Concretamente los citados principios se adoptaron mediante el acuerdo del Consejo de Administración RTVE del 28 de julio de 1981.

51 El citado precepto dispone que: "salvaguardando los principios de libertad religiosa y de expresión, el Estado velará para que sean respetados en sus medios de comunicación social los sentimientos de los católicos y establecerá los correspondientes acuerdos sobre estas materias con la Conferencia episcopal española”. En este sentido, entre otros, véase RODRÍGUEZ GARCÍA, J. A.: El control de los medios de comunicación, ob. cit., p. 234.

52 Los mencionados convenios son los siguientes: Acuerdo entre la Radiotelevisión andaluza y los Obispos de la diócesis de Andalucía de 26 de octubre de 1989 (modificado por el protocolo para interpretación y desarrollo, de 22 de febrero de 1990) y el acuerdo entre Radiotelevisión de Galicia y los obispos de la Diócesis del territorio de la Comunidad Autónoma de Galicia de 25 de marzo de 1991. Por otro lado, también existen acuerdos de los Consejos de Administración de los entes públicos de Radiotelevisión de Cataluña y País Vasco sobre estas materias.

53 En la actualidad, las citadas confesiones religiosas disponen de espacios de emisión en TVE en virtud de un acuerdo firmado entre los representantes de las religiones musulmana, judía y evangélica, el Ministerio de Justicia y la Dirección general de RTVE. 
Para finalizar el presente punto, y a modo de recapitulación general sobre el reconocimiento y desarrollo del derecho de acceso, se deben realizar las apreciaciones siguientes:

1. ${ }^{a}$ En relación con los grupos políticos significativos se garantiza de manera suficiente su derecho a tiempo de antena tanto en periodos electorales como durante la campaña previa a la convocatoria de un referéndum. No se puede decir lo mismo durante las emisiones ordinarias dado que, como se ha enunciado, la atribución de la potestad de determinación de los tiempos de antena gratuitos a un órgano administrativo con excesiva dependencia de la mayoría parlamentaria de turno ha llevado a su práctica inaplicación. En consecuencia, como advierte acertadamente Rallo Lombarte, "los grupos políticos sólo gozan de un auténtico derecho de acceso a los medios de comunicación públicos quince días cada legislatura o con motivo de la celebración de un referéndum ${ }^{54}$.

2. ${ }^{a}$ Respecto de los grupos sociales representativos no religiosos (sindicatos, ONGS, organizaciones empresariales) el legislador se ha limitado exclusivamente a establecer unas pautas para su determinación, pero en la práctica no ha materializado su derecho de acceso ya que no ha desarrollado los elementos necesarios para su ejercicio como, por ejemplo, los criterios de asignación de los espacios gratuitos o un procedimiento administrativo que regule su ejercicio.

3. ${ }^{a}$ En el acceso de los grupos religiosos se considera que no se observa lo establecido en el artículo 20.3 de la Constitución, puesto que este artículo establece claramente que la ley "garantizará" su acceso, no un órgano gestor de un medio de comunicación público. Por otro lado, sigue existiendo una manifiesta desigualdad entre los distintos grupos sociales significativos. Se considera que la programación religiosa es desproporcionada en función de que no se ha reconocido el ejercicio del derecho de acceso a otros grupos sociales y políticos en periodos no electorales.

4. ${ }^{a}$ El derecho de acceso reconocido en el artículo 20.3 se resuelve de manera insuficiente pues no se regula para los medios de comunicación gestionados por las entidades locales.

Por todo ello, se concluye que todavía falta un largo camino por recorrer para garantizar un auténtico derecho de acceso a los medios de comunicación dependientes del Estado. De su correcto y efectivo reconocimiento depende el eficaz funcionamiento del Estado social y democrático de Derecho. Para que se forme una verdadera opinión pública es imprescindible que el Estado ponga a disposición de los ciudadanos una tribuna o plataforma para ejercitar las libertades de expresión e información. Asimismo, y no por ello menos importante, del correcto desarrollo del derecho de acceso depende la preservación del pluralismo interno de los medios de comunicación públicos. 


\section{ALGUNAS PROPUESTAS DE LEGE FERENDA}

Ya han pasado más de 25 años desde la aprobación de la Constitución y la garantía del acceso a los medios de comunicación dependientes del Estado continúa siendo una asignatura constitucional pendiente. Por ello, es ineludible una legislación que desarrolle y garantice el citado acceso de acuerdo con el mandato del artículo 20.3 de la Constitución y que, a su vez, sea coherente con el modelo de Estado establecido en el artículo 1 de la misma. Para ello, se considera conveniente tomar, entre otras, las siguientes medidas:

1. ${ }^{a}$ Es de vital importancia modificar el ERTV con el objeto de establecer tiempos de antena estrictos destinados al ejercicio del derecho de acceso en la programación ordinaria del citado medio. Esta idea también debe ser extensible a los medios de comunicación autonómicos y locales dado que se considera que la referencia que efectúa el artículo 20.3 de la Constitución a los «medios de comunicación dependientes del Estado" también los incluye.

2. ${ }^{a}$ Se deben instaurar criterios objetivos de distribución de tiempos y horarios de antena para el ejercicio del derecho de acceso en la programación anual de los medios de comunicación públicos. Un buen referente en esta materia lo constituye la LOREG dado que otorga un número determinado de minutos en los espacios públicos de radiotelevisión a los partidos políticos atendiendo a dos criterios: uno de igualdad mínima que, en lo que importa ahora, se establecería de forma idéntica para todos los grupos políticos y sociales significativos con el objeto de asegurar a todos ellos la oportunidad de poder expresar sus ideas e informaciones libremente. Y otro proporcional, atendiendo a criterios objetivos que pongan de manifiesto su peso en la sociedad como, por ejemplo, el número su número de afiliados o la cantidad de asistentes a sus convocatorias públicas.

En este sentido, el artículo 20.3 de la Constitución hace referencia a que la ley "garantizará" el acceso a los medios de comunicación públicos, por consiguiente, el régimen básico debe estar establecido por una disposición de carácter legal, esto es, en el caso del acceso ordinario, en el ERTV. Lo anterior no impide que la aludida disposición legal pueda ser desarrollada por un reglamento específico del derecho de acceso que regule cuestiones como, por ejemplo, el procedimiento administrativo de solicitud de los espacios gratuitos.

3. ${ }^{a}$ La distribución de los tiempos de antena debería determinarse por acuerdo entre los grupos sociales significativos y el Consejo de Administración del Ente público de radiotelevisión. Sobre la cuestión, parece aconsejable que se modifique la actual composición del citado Consejo de Administración con el objeto de evitar la excesiva dependencia de las mayorías parlamentarias que genera su actual sistema de designación ${ }^{55}$. En este sentido, el informe para la re-

55 En la actualidad, en virtud de lo establecido en el artículo 7 del ERTV, el Consejo de Administración de la televisión pública se compone de doce miembros, elegidos para cada legislatura, la mitad por el Congreso de los Diputados y la mitad por el Senado, mediante mayoría cualificada de dos tercios de cada Cámara, entre personas de relevantes méritos profesionales. 
forma de los medios de comunicación públicos propone que el aludido órgano se componga de ocho miembros caracterizados por sus relevantes méritos en el mundo de la comunicación y que su elección ya no dependa exclusivamente de las Cámaras parlamentarias ${ }^{56}$.

4. ${ }^{a}$ Asimismo parece oportuno atribuir el control del cumplimiento efectivo del acceso a un órgano externo e independiente, sin menoscabar con ello las competencias de fiscalización del Congreso de los Diputados sobre la materia. La aludida función la podría desempeñar un Consejo Audiovisual, todavía inexistente en el ámbito nacional, pero sí en algunas Comunidades Autónomas $^{57}$. Más en concreto, el citado Consejo Audiovisual actuaría como garante del cumplimiento por parte de los medios de comunicación públicos del derecho de acceso y, en caso de inobservancia o desacuerdo, sería la instancia superior que dirimiera el litigio.

5. ${ }^{\mathrm{A}}$ El artículo 20.3 de la Constitución sólo establece la obligación de que la ley garantice el derecho de acceso de los grupos sociales y políticos significativos, sin embargo, esto no debería impedir que también se extendiera legislativamente este derecho a los grupos de menor significación, fundamentalmente por dos razones:

De un lado, esta posibilidad no está vedada pues la Constitución sólo obliga a garantizar el acceso a los grupos políticos o sociales significativos, pero no prohíbe extender el acceso a los grupos que no posean el carácter de significativos, siempre que con dicho acceso no se restrinja o desnaturalice el acceso de los primeros. Por esto, las normativas reguladoras de los canales públicos de varias Comunidades Autónomas también contemplan el acceso de grupos sociales y políticos de menor significación ${ }^{58}$.

56 Concretamente el citado informa recomienda que la elección del Consejo de Administración de RTVE se efectúe a razón de: «1. Cuatro miembros elegidos para cada mandato, la mitad por el Congreso (2) y la mitad por el Senado (2), mediante mayoría reforzada de dos tercios de la Cámara correspondiente, a propuesta de al menos la mitad de los Grupos parlamentarios existentes redondeada al alza. Y previo examen de la idoneidad ante la Comisión parlamentaria correspondiente. 2. Dos miembros elegidos por el Consejo Audiovisual, por mayoría de al menos dos tercios de sus miembros. 3. Dos miembros designados por los sindicatos más representativos en RTVE». Véase Informe para la reforma de los medios de comunicación de titularidad del Estado, de febrero de 2005, p. 135.

57 En la actualidad, en el ámbito autonómico existen dos Consejos Audiovisuales, el de Cataluña que se regula en el Texto Refundido de la Ley $2 / 2002$, de 4 de mayo, del Consejo Audiovisual de Cataluña, y el de Navarra que se rige por lo dispuesto en la Ley Foral 18/2001, de 5 de julio, modificada por la Ley Foral 17/2002, de 6 de junio. Por otro lado, sobre el "Conseil Supérieur de l'Audiovisuel" de Francia, entre otros, véanse RALLO LOMBARTE, A.: Pluralismo informativo y Constitución, ob. cit., p. 237 y ss, RODRÍGUEZ GARCÍA, J. A.: El control de los medios de comunicación, ob. cit., p. 87 y ss. Sobre la "Federal Communications Commission" de los Estados Unidos, véanse RALLO LOMBARTE, A.: Pluralismo informativo y Constitución, ob. cit., p. 285 y ss, RODRÍGUEZ GARCÍA, J. A.: El control de los medios de comunicación, ob. cit., p. 139 y ss.

58 Sobre la cuestión, entre otros, véanse artículo 6.1 k) y artículo 16 de la Ley 13/1984, de 30 de junio, de creación, organización y control de Radio Televisión Madrid; artículo 21 de la de la Ley 7/1984, de julio, de creación de la entidad pública radio televisión valenciana y regulación de los 
De otro lado, los grupos minoritarios no tienen la posibilidad, dada la escasez de recursos de que disponen la mayoría de ellos, de acceder a una tribuna para transmitir sus opiniones e informaciones. Además, la aludida medida tendería a aumentar el pluralismo interno de los medios de comunicación públicos, con la consecuente mejora de la formación de la opinión pública libre.

6. ${ }^{\circ}$ La legislación de desarrollo del derecho de acceso debería disponer expresamente que el servicio público de radiotelevisión pondrá a disposición de los grupos sociales y políticos los medios materiales y personales necesarios para la producción de los espacios destinados a su ejercicio ${ }^{59}$. Esta propuesta se justifica esencialmente por las siguientes razones: en primer lugar, porque, según la interpretación del derecho de acceso sostenida, éste se identifica con el derecho de los grupos sociales y políticos significativos a tiempos de antena "gratuitos" en los medios de comunicación públicos. En segundo lugar, el derecho de acceso a los medios de comunicación públicos posibilita, entre otras cuestiones, que los que no disponen de los medios económicos para sufragar un medio de comunicación accedan al libre mercado de las ideas. Si los grupos sociales y políticos no tienen medios para lo anterior, también es probable que carezcan de los medios materiales y personales necesarios para la producción de sus propios programas. Y, en tercer lugar, que el servicio público de radiotelevisión sufrague los costes de producción de los aludidos espacios posibilitará la igualdad entre los distintos grupos en el ejercicio del derecho de acceso.

En relación con lo anterior, la profesora Castro Jover, para realizar una mejor distribución de los espacios públicos y evitar la posición dominante de determinados grupos, mantiene que se debería tener en cuenta que los grupos significativos que pretendan ejercitar su derecho de acceso no dispongan de medios de difusión propios, ya sea como titulares o en régimen de concesión $^{60}$.

ABSTRACT. In Spain, a reformation about all the media linked to the state is taking place. One of the questions that will be treated along this reformation is the regulation of the most remarkable social and political groups right to access to state media, since in the Spanish Constitution (Art. 20.3) we can find, inside the range of concrete guarantees about the freedom of expression and

servicios de radio difusión y televisión de la Generalidad Valenciana; el artículo 21.1 de la Ley 5/1982, de 20 de mayo, de creación del Ente público "Radio Televisión Vasca".

59 En este sentido, el Informe para la reforma de los medios de comunicación de titularidad del Estado propone que los espacios destinados para el ejercicio del derecho de acceso "serán realizados por RTVE con sus propios medios técnicos y humanos, para garantizar tanto la calidad profesional de su elaboración como el máximo atractivo y alcance para las audiencias". Véase Informe para la reforma de los medios de comunicación de titularidad del Estado, p. 103.

60 Véase CASTRO JOVER, A.: "Contribución al estudio del derecho de acceso a los medios de comunicación", ob. cit., p. 655 y ss. 
information, that the law will guarantee that mentioned access. This article tries to demonstrate that the recognition of the right to access to the public media involves a review of the liberal model of public communication and, consequently, the Spanish Constitution of 1978 decided to reconsider the whole of the liberties related to public communication, paying attention to the social and political functions that they entail in the social and democratic State, subject to the rule of law. Later, it has been proved that the regulation about this subject, which has been in force for more than 25 years, has not fulfilled this constitutional order. Finally, some "lege ferenda" proposals are made, in order to create a regulation for the right to access as coherent as possible with the social and democratic State, subject to the rule of law. 